\title{
The global financial crisis and Australian general practice
}

\author{
lan S. McRae ${ }^{1,3}$ BSc, MSc, BA, PhD, Research Fellow \\ Francesco Paolucci ${ }^{2}$ BEcon, MSc, PhD, Research Fellow \\ ${ }^{1}$ Australian Primary Health Care Research Institute, The Australian National University, \\ Building 62, Level 1, Ian Potter House, Corner of Marcus Clarke and Gordon Streets, \\ Australian National University, Acton, ACT 0200, Australia. \\ ${ }^{2}$ Australian Centre for Economic Research on Health, The Australian National University, \\ Building 62, Mills Road, Acton, ACT 0200, Australia. Email: francesco.paolucci@anu.edu.au \\ ${ }^{3}$ Corresponding author. Email: ian.s.mcrae@anu.edu.au
}

\begin{abstract}
Objective. To explore the potential effects of the global financial crisis (GFC) on the market for general practitioner (GP) services in Australia.

Design. We estimate the impact of changes in unemployment rates on demand for GP services and the impact of lost asset values on GP retirement plans and work patterns. Combining these supply and demand effects, we estimate the potential effect of the GFC on the market for GP services under various scenarios.

Results. If deferral of retirement increases GP availability by $2 \%$, and historic trends to reduce GP working hours are halved, at the current level of $\sim 5.2 \%$ unemployment average fees would decline by $\$ 0.23$ per GP consultation and volumes of GP services would rise by $2.53 \%$ with almost no change in average GP gross earnings over what would otherwise have occurred. With $8.5 \%$ unemployment, as initially predicted by Treasury, GP fees would increase by $\$ 0.91$ and GP income by nearly $3 \%$.

Conclusions. The GFC is likely to increase activity in the GP market and potentially to reduce fee levels relative to the pre-GFC trends. Net effects on average GP incomes are likely to be small at current unemployment levels.

What is known about the topic? Although the broad directions of the impact of the global financial crisis on the demand for and supply of GP services have been the subject of public discussion, the overall impact on the GP market has not been formally assessed.

What does this paper add? Drawing on existing supply and demand models, we estimate the likely effect of the global financial crisis on GP activity levels, GP earnings, and the fees to be faced by patients.

What are the implications for practitioners? Practitioners on average are likely to work harder to recover losses in the investments they have made for their retirements. They may face lower fees than would have been the case due to the increasing supply of GPs as some defer retirement, but average incomes are likely to be minimally affected.
\end{abstract}

\section{Introduction}

The global financial crisis (GFC) is having (and will continue to have) an impact on the health sector in Australia as in many other countries. The impact on the health sector will vary depending on health financing arrangements, welfare funding arrangements and the size of the economic shock in different countries. In some countries this impact may require a government response whereas in others it will not. The size and nature of appropriate responses will also vary.

This paper explores the likely impact of the GFC on Australian general practice. It both provides a view of whether any policy response is needed in this sector in Australia, and also provides a methodology which may be of relevance in other environments.

\section{Background}

The GFC in Australia has already had a range of measurable effects, including increasing unemployment rates and reducing values of investments. Unemployment rose from $4.2 \%$ in 2008 to a peak of $5.8 \%$ in mid-2009, falling back to $5.4 \%$ by April $2010 .{ }^{1}$ The value of shares fell $\sim 50 \%$ on average, with the ASX 200 measure of Australian share values falling from a peak of just over 6000 to 3100 in March 2009. The share values recovered but in May 2010 were still $\sim 25 \%$ below the peak. Even conservative investment arrangements fell $\sim 20 \%$ at the lowest point, and were still on average $\sim 12 \%$ below 2007 levels. $^{2}$

Rising unemployment ${ }^{3-5}$ is expected to increase demand for medical services, and the supply of medical services is likely to increase as doctors defer retirement ${ }^{6}$ due to the falling value of 
their investments. This paper examines the combined effects of the GFC on demand and supply in the Australian market for general practice services.

The GFC will influence demand for general practitioner (GP) services through rising unemployment levels. This will arise through a mixture of health effects and economic effects. The international evidence on mortality effects of unemployment is mixed, ${ }^{7-10}$ but there is evidence that unemployment influences morbidity and use of GP services. ${ }^{11-13}$ Unemployment will also mean people have more time in which they can attend a GP, and will increase the probability that the person will be bulk billed (face no out-of-pocket costs), so reducing economic barriers to visiting a GP. These factors will lead to greater demand for medical services. ${ }^{14-16}$

The GFC will also have an impact on the supply of GP services. A survey undertaken for the Medical Observer ${ }^{6}$ reported that $39 \%$ of GPs intended to delay their retirement plans due to the impact of the GFC on their retirement savings and investments. A large number of GPs were planning to retire over the next few years according to studies conducted before the GFC. ${ }^{17,18}$ The MABEL survey conducted by the University of Melbourne ${ }^{18}$ reported that $11.6 \%$ of GPs were 'very likely' to quit medicine altogether in the next 5 years. Assuming these $11.6 \%$ were spread evenly over the 5 years, this would mean $2.3 \%$ retirement per year, or if these GPs did not retire $2.3 \%$ more GPs in practice than would otherwise have been the case.

Since the mid-1990s there has been a downward trend in the number of services provided per GP, even after adjusting for feminisation and other structural changes in general practice. ${ }^{19,20}$ If GPs are concerned about maintaining their retirement investments during the economic downturn, it is likely that this trend will be reduced at least temporarily further increasing the supply of GP services relative to existing trends.

The overall effect of the GFC will therefore depend on the joint effects of changes in supply of and in demand for GP services, and these joint effects are discussed below.

\section{Methods}

We have estimated the potential impact of the GFC on supply of and demand for GP services, relative to 2008, using equations developed by McRae. ${ }^{14}$

The demand equation, as in most similar studies in Australia and internationally, ${ }^{21,22}$ shows a clear response of demand to prices, with demand falling by $2 \%$ for a $10 \%$ increase in out-ofpocket costs. It also depends on a range of other factors including unemployment levels. Holding all other factors constant and changing unemployment levels allows us to estimate the change in the demand curve due to the GFC.

The supply equation depends, among other things, on the overall number of GPs working in Australia and the ongoing trend to lower average service provision per GP. Again holding all other factors constant and varying these factors enables us to estimate the change in the supply curve due to the GFC.

Examining the interaction between the supply and demand effects enables the potential changes in overall service volumes, volumes per GP, gross and net fees charged, and hence the likely impact on average GP gross earnings to be estimated.
As unemployment levels were initially predicted by the Australian Treasury ${ }^{3}$ to reach $8.5 \%$, they have been tested at various levels from unchanged at 4.2 to $8.5 \%$. The impact of the GFC on retirement patterns has been tested as if there were no change in retirement levels, $2 \%$ deferring retirement, or $4 \%$ deferring retirement. The impact of the GFC on the underlying trends in patterns of reduced GP work is tested with the trend continuing unabated, diminishing to half its previous levels, or ceasing for the period of the economic downturn.

The original supply and demand equations were estimated ${ }^{14}$ as part of a system of structural equations linking supply, demand, price, mortality and an array of exogenous variables. The estimates are based 8 years of data from 1996 to 2003 drawn from Medicare administrative data, Population Census data and other sources aggregated to 816 areas based on Statistical Local Areas (SLAs).

\section{Results}

Figure 1 shows how the estimated supply and demand curves for 2008 would change if it was assumed that a group of GPs previously planning to retire did not do so adding $2 \%$ of to the supply of GPs (about one years complement of potential retirees), that the trend to lower work hours of GPs diminished by half for the duration of the downturn but did not disappear, and the $8.5 \%$ unemployment rate initially predicted by Treasury eventuated. The figure shows the 2008 outcome of 5.18 services per capita at an average gross fee per service of $\$ 45.20$ where the 2008 supply and demand curves cross, and the outcome under these GFC assumptions of 5.33 services per capita at an average fee (in 2008 dollars) of $\$ 46.11$ per service.

Table 1 shows the overall impact of the GFC on fees and services under the same assumptions about GP supply, but across the range of potential unemployment levels. As would be expected with increasing supply of GPs the number of services

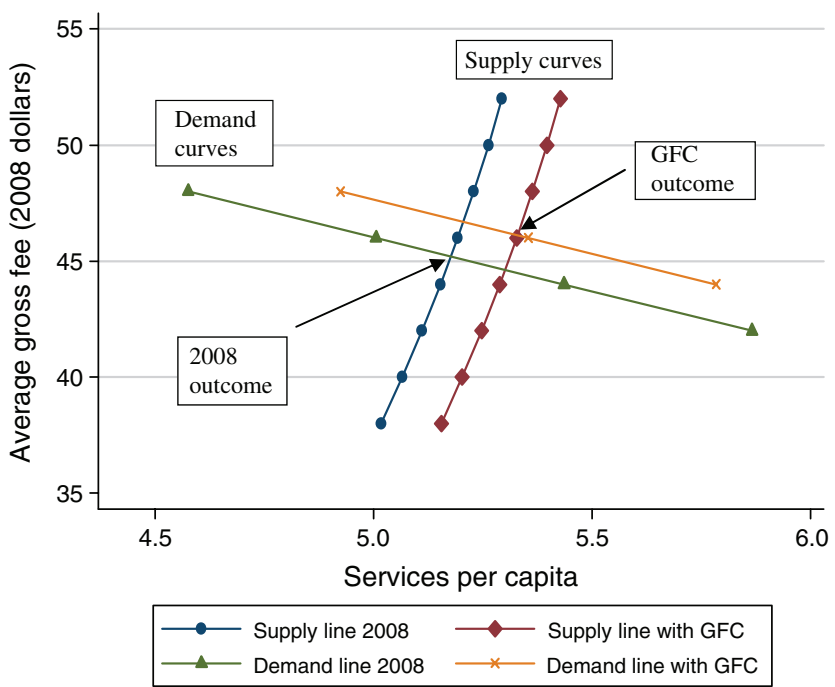

Fig. 1. Supply and demand curves: 2008 and with GFC impact. Note it is assumed: the downward trend in services per GP is halved; $2 \%$ of GPs remain in the workforce rather than retiring; and unemployment reaches $8.5 \%$ as predicted by Treasury in 2009 . 
Table 1. Impact of changes caused by the GFC on the GP market: impact of various levels of unemployment

Note it is assumed: the downward trend in services per GP is halved; and 2\% of GPs remain in the workforce rather than retiring

\begin{tabular}{|c|c|c|c|c|}
\hline & \multicolumn{4}{|c|}{ Estimated level of unemployment (was $4.2 \%$ in 2008) } \\
\hline & $4.2 \%$ & $5.2 \%$ & $5.8 \%$ & $8.5 \%$ \\
\hline Impact on gross fees charged (2008 dollars) per service & $-\$ 0.58$ & $-\$ 0.23$ & $-\$ 0.03$ & $\$ 0.91$ \\
\hline Impact on average gross fees charged per GP & $-0.90 \%$ & $0.00 \%$ & $0.54 \%$ & $2.97 \%$ \\
\hline
\end{tabular}

Table 2. Impact of changes caused by the GFC on the GP market: impact of different changes in GP supply Note: it is assumed unemployment increases from $4.2 \%$ to $5.2 \%$

\begin{tabular}{|c|c|c|c|}
\hline & \multirow{3}{*}{ No change } & \multicolumn{2}{|c|}{ Change in GP supply from 2008} \\
\hline & & $\begin{array}{l}2 \% \text { of GPs remain in the } \\
\text { workforce rather than retiring }\end{array}$ & $\begin{array}{l}4 \% \text { of GPs remain in the } \\
\text { workforce rather than retiring }\end{array}$ \\
\hline & & $\begin{array}{l}\text { The downward trend in } \\
\text { services per GP is halved }\end{array}$ & $\begin{array}{l}\text { The downward trend } \\
\text { in services per GP ceases }\end{array}$ \\
\hline Impact on gross fees charged (2008 dollars) per service & $\$ 0.35$ & $-\$ 0.23$ & $-\$ 0.82$ \\
\hline Impact on GP services per capita as a percentage of 2008 levels & $0.13 \%$ & $2.53 \%$ & $4.96 \%$ \\
\hline Impact on average gross fees charged per GP & $0.90 \%$ & $0.00 \%$ & $-0.91 \%$ \\
\hline
\end{tabular}

increases regardless of the change in unemployment levels, whereas the impact on fees depends on the unemployment levels. The effect on the average gross fee charged, under the supply assumptions in Table 1 , is $-\$ 0.23$ at an unemployment rate of $\sim 5.2 \%$, which is approximately the rate in early 2010 .

If the impact of the GFC on retirement or on GP activity levels was less than assumed in Table 1 and Fig. 1, the GFC supply line in Fig. 1 would be closer to the 2008 supply line, meaning the fee increases and income increases would be greater, but the volume increase less. At the extreme, if the GFC had no impact on GP supply but unemployment increased to $5.2 \%$, fees would increase by $\$ 0.35$ and services by $0.13 \%$ or 0.01 services per capita.

If, on the other hand, the impact on supply was greater than is shown in Fig. 1, the GFC supply line would move further from the 2008 line. For example, if the number of GPs was 4\% higher than without the GFC, and the trend to less services per GP completely evaporated, then (at 5.2\% unemployment) fees would decline by $\$ 0.82$ per service and services per capita would grow $4.96 \%$ or 0.25 services per capita. Table 2 shows the potential outcomes with different supply responses by GPs.

\section{Discussion}

Although the precise effects of the GFC cannot be estimated without knowing the peak level of unemployment and the actual effect on GP behaviour, GPs are unlikely to face unmanageable demand or loss of income due to the GFC.

There is also no need for unemployed patients to fear they will face longer waits or higher costs of seeking GP care as the supply of GP services is likely to increase. Unemployed people in Australia are generally able to access government health care concession cards. Although there is no obligation to do so, most GPs bulk bill most concession card holders. ${ }^{23}$

This is not inconsistent with increasing overall fees, as GPs are able to increase gap fees charged to patients who are not bulk billed, and a trend to more bulk billing combined with higher gap payments has been evident for the last 4 years. ${ }^{24}$ If gross fees increase under the GFC, however, those patients facing gap charges are likely to face higher out-of-pocket costs than would have arisen without the GFC.

If the unemployment rate remains stable at approximately the current levels as predicted by Treasury ${ }^{4}$ then the overall outcome depends on the GP supply response. Volumes of services will be higher than they would be in the absence of the GFC, and average fees per service may increase or decline. Overall impacts on average GP incomes are likely to be small. Given the ongoing volatility in financial markets the longer term outcomes are still uncertain. The study shows how the outcome in the GP market would vary under different assumptions about the direct impacts of the GFC on unemployment and GP behaviour.

These estimates show changes relative to the outcomes with no GFC. There are many other determinants of GP market outcomes including any government changes to the Medicare rebate or the rules for overseas trained doctors, or the impact of H1N1 swine flu. The ageing and feminisation of the GP workforce, increasing numbers of medical school graduates and the ageing and increasing levels of chronic illness in the community as a whole will also influence supply and demand in the GP market.

Overall, the most likely impact of the GFC on the GP market in Australia appears to be higher volumes of activity driven by both demand increases and by increases in supply of GP services offered, a small shift in fees with offsetting demand and supply effects, and little net effect on average GP incomes.

\section{Competing interests}

The authors declare that no conflicts of interest exist.

\section{Acknowledgements}

The authors gratefully acknowledge the contribution of Laurann Yen at the Australian Primary Health Care Research Institute to the writing of this paper. 


\section{References}

1 The Labour Force. Cat No 6202.0. Canberra: Australian Bureau of Statistics; 2010.

2 Super Ratings. Latest Returns. 2010 [update]. Available at http://www. superratings.com.au/latestreturns [verified 31 May 2010].

3 The Budget at a Glance. Australian Treasury; 2009. Available at http:// www.budget.gov.au/2009-10/content/at_a_glance/html/at_a_glance.htm [verified 25 June 2009].

4 The Budget at a Glance. Australian Treasury; 2010. Available at http:// www.budget.gov.au/2010-11/content/overview/html/overview_02.htm [verified 31 May 2010].

5 Press Release: Unemployment, working poor and vulnerable employment to increase dramatically due to global economic crisis. International Labour Organization; 2009. Available at http://www.ilo.org/global/ About_the_ILO/Media_and_public_information/Press_releases/lang-en/ WCMS_101462/index.htm [verified 2 July 2009].

6 Medical Observer Staff Writers. Fees drop forecast to ease the squeeze on patients. Medical Observer 2009; 2009(8 May): 1-2.

7 Jin RL, Shah CP, Svoboda TJ. The impact of unemployment on health: a review of the evidence. CMAJ 1995; 153(5): 529-40.

8 Ruhm CJ. Are recessions good for your health? Q J Econ 2000; 115(2): 617-50. doi:10.1162/003355300554872

9 Gerdtham UG, Ruhm CJ. Deaths rise in good economic times: evidence from the OECD. Econ Hum Biol 2006; 4: 298-316. doi:10.1016/j. ehb.2006.04.001

10 Böckerman P, Johansson E, Helakorpi S, Prättälä R, Vartiainen E, Uutela A. Does a slump really make you thinner? Finnish micro-level evidence 978-2002. Health Econ 2007; 16: 103-7. doi:10.1002/hec.1156

11 Marmot MG. Understanding Social Inequalities in Health. Perspect Biol Med 2003; 46(3): S9-23. doi:10.1353/pbm.2003.0056

12 Artazcoz L, Benach J, Borrell C, Cortès I. Unemployment and mental health: understanding the interactions among gender, family roles, and social class. Am J Public Health 2004; 94(1): 82-8. doi:10.2105/ AJPH.94.1.82

13 Carr-Hill RA, Rice N, Roland M. Socioeconomic determinants of rates of consultation in general practice based on fourth national morbidity survey of general practices. BMJ 1996; 312(7037): 1008-12.
14 McRae I. Supply and demand for GP services in Australia. ACERH Research Report Number 6. Canberra: ANU; 2009. Available at http:// www.acerh.edu.au/publicationsrrwp.php [verified 31 May 2010].

15 Pohlmeier W, Volker U. An econometric model of the two part decision making process in the demand for health care. J Hum Resour 1995; 30(2): 339-61. doi:10.2307/146123

16 Bago d'Uva T. Latent class models for use of primary care: evidence from a British panel. Health Econ 2005; 14(9): 873-92. doi:10.1002/hec.1047

17 Brett TD, Arnold-Reed DE, Hince DA, Wood I, Moorhead R. Retirement intentions of general practitioners aged 45-65 years. Med J Aust 2009; 191(2): 75-7.

18 MABEL Team. MABEL Matters, No. 1 May 2009, 2009. Available at https://mabel.org.au/newsletter/May\%202009.pdf [verified 23 June 2009].

19 McRae I. Australian general practice: where have all the GP services gone? Appl Health Econ Health Policy 2006; 5(2): 117-24. doi:10.2165/ 00148365-200605020-00005

20 Charles J, Britt H, Valenti L. The evolution of the general practice workforce in Australia, 1991-2003. Med J Aust 2004; 181(2): 85-90.

21 Richardson J. Supply and demand for medical care: or is the health care market perverse? Aust Econ Rev 2001; 34: 336-52. doi:10.1111/14678462.00203

22 Manning WG, Newhouse P, Duan N, Keeler E, Leibowitz A, Marquis M. Health insurance and the demand for medical care: evidence from a randomized experiment. Am Econ Rev 1987; 77: 251-77.

23 Concession Card Holders, Response to Question on Notice from Senator Allison. Canberra: Department of Health and Ageing; 2003.

24 Medicare Statistics: March Quarter 2010. Canberra: Department of Health and Ageing; 2010. Available at http://www.health.gov.au/ internet/main/publishing.nsf/Content/medstat-mar10-tables-ba [verified 4 June 2010].

Manuscript received 10 September 2009, accepted 15 June 2010 